\title{
GAS TURBINE DIAGNOSIS USING A FAULT ISOLATION ENHANCED GPA
}

\author{
Y. G. Li
}

\author{
School of Engineering, Cranfield University, Bedford MK43 OAL, ENGLAND
}

\section{ABSTRACT}

Gas Path Analysis (GPA) and its different derivatives have been developed for more than thirty years and used widely and successfully by many gas turbine manufacturers and operators. In gas turbine gas path component diagnosis, it has been recognized for a long time that GPA would be more successful if degraded components could be located. Unfortunately, only the deviation of measurable parameters is monitored in operation and information about the degraded components is normally not available. In this research, a two-step diagnostic approach is introduced, where a pattern matching method is used first and further developed to isolate degraded components; then Gas Path Analysis is applied to assess the quantity of degradation. A gas turbine performance simulation program, Cranfield University TURBOMATCH, has been modified to simulate the diagnostic process. A model gas turbine engine similar to Rolls-Royce aero AVON is used to test the effectiveness of the approach. It is found that the developed fault isolation method can isolate degraded components accurately and enhance the effectiveness of the quantitative assessment of the degradation with Gas Path Analysis (GPA) in gas turbine diagnostics.

\section{KEYWORDS}

Gas Turbine, Diagnosis, GPA, Fault Isolation, Pattern Matching, Fault Isolation

\section{NOMENCLATURE}

$F C \quad$ Fault case

GPA Gas Path Analysis

$H \quad$ Influence Coefficient Matrix (ICM)

$H^{-1} \quad$ Fault Coefficient Matrix (FCM)

\section{$\vec{i}$}

$m f$

$M D F$

MRFSE

$M$

$N$

$\bar{N}$

$P$

$S F$

$S F C$

SFSE

$T$

$\vec{V}$

$\vec{v}$

$\vec{V}_{0}$

$x$

$\Delta \vec{x}$

$z$

$\bar{Z}$

$\Delta \vec{z}$

$\sigma_{1}-\sigma_{4}$

$\eta$

$\Gamma$

\begin{tabular}{lll} 
Subscripts & \\
\hline$b$ & & burner \\
$c$ & compressor \\
$i, j$ & index \\
$n$ & nominal
\end{tabular}

Unity vector vector

Thresholds
Fuel flow rate $(\mathrm{kg} / \mathrm{s})$

Matching Displacement Factor

Maximum Ratio of Fault Signature Elements

Number of measurement samples

Number of measurable parameters

Relative non-dimensional speed (\%)

Total pressure (atm)

Similarity Factor

Specific Fuel Consumption $(\mathrm{mg} / \mathrm{N} / \mathrm{sec})$

Sign of Fault Signature Elements

Total temperature (K)

Fault signature vector

Unity fault signature vector

Actual fault signature vector

Independent parameter

Engine component parameter deviation

Dependent (measurable) parameter

Average measurement

Measurable parameter deviation vector

Isentropic efficiency

Flow capacity 


$\begin{array}{ll}n d & \text { non-dimensional } \\ t & \text { turbine } \\ 3 & \text { compressor exit } \\ 8 & \text { turbine exit }\end{array}$

\section{INTRODUCTION}

Gas path diagnostics techniques have been developed for more than thirty years and shown great potential to improve the availability of gas turbines and cut down the maintenance cost of gas turbine engines. Li [2002] and Singh [2003] have provided comprehensive reviews on gas turbine diagnostic techniques. The most important ones among these diagnostic techniques are gas path analysis (GPA) and its derivatives (Urban [1975], Doel [1993], Volponi [1982], Escher and Singh [1995]), traditional optimization based non-linear methods (Stamatis et al. [1990]), artificial neural networks (Denny [1993], Zedda and Singh [1999a]), genetic algorithms (Zedda and Singh [1999b], Gulati et al. [2001], Sampath et al. [2002]), fuzzy expert systems (Ganguli [2001a], Marinai et al. [2003]) and diagnostics with transient measurement ( $\mathrm{Li}$ [2003]).

Gas path analysis (GPA) and its derivatives are powerful diagnostic approaches, although they require certain conditions (Doel [1993]) to work well, and they suffer from disadvantages such as the "smearing" effect. It has been evident for a long time that if degraded gas turbine components can be located with a priori information, GPA approaches can be very successful in quantifying the degradation. This idea has been discussed by many researchers, such as Mathioudakis [2003].

The source of the a priori information may be different; one of which is the fault isolation technique. Different gas turbine fault isolation techniques, such as artificial neural networks (ANN) (Ogaji and Singh [2003]) and pattern matching method (Lee and Singh [1996]) have been developed. In this paper, the fault pattern matching method introduced by Lee and Singh [1996] has been developed further, used to isolate degraded gas turbine components and initially quantify the degradation. Once the degraded components are located, non-linear GPA is used to refine the degradation assessment. The developed approach has been applied to a model gas turbine similar to Rolls-Royce aero AVON to test the effectiveness of the approach.

\section{MODEL GAS TURBINE ENGINE AND ITS PERFORMANCE SIMULATION}

A representative model gas turbine engine similar to Rolls Royce aero AVON is chosen for the analysis. It is a one-shaft turbojet engine with one compressor, one burner and one turbine. When the engine works in certain operating conditions, the shaft rotational speed is used as the control parameter and kept constant as environmental condition changes and degradation happens. The configuration of the model engine is illustrated in Figure 1. The basic performance parameters of the engine are as follows [Wilkenson, 1960]:

$\begin{array}{ll}\text { Total mass flow rate } & 76 \mathrm{~kg} / \mathrm{s} \\ \text { Total pressure ratio } & 8.75 \\ \text { Turbine entry temperature } & 1141 \mathrm{~K} \\ \text { Thrust } & 46.6 \mathrm{kN} \\ \text { SFC } & 20.4 \mathrm{mg} / \mathrm{N} / \mathrm{sec}\end{array}$

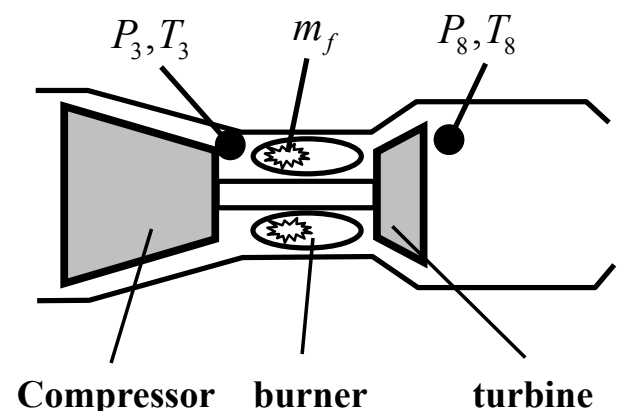

Figure 1. Model gas turbine configuration

The performance of the model engine was simulated with Cranfield gas turbine performance simulation software TURBOMATCH (Macmillan [1974]), the validity of which has been tested over many years.

Both the clean and degraded engine performances are simulated with TURBOMATCH. In the situation where the engine is degraded, the degradation of the engine components is simulated with a reduction in flow capacity and isentropic efficiency for the compressor and turbine, and combustion efficiency for the burner.

To assist the diagnostics research, it is assumed that the turbine of the model engine is degraded and a degradation of $3.5 \%$ reduction in flow capacity and $1.5 \%$ reduction in isentropic efficiency is implanted into the turbine. It is also assumed that the compressor, the burner and the turbine of the gas turbine engine concerned are potential degraded components in operation and the number of simultaneously degraded components can be up to two.

\section{MEASUREMENT SIMULATION MEASUREMENT NOISE REDUCTION}

AND

It is assumed that the instrumentation set for the following measurements is available for the diagnosis of the model engine (Figure 1):

- Compressor discharge total pressure $\left(P_{3}\right)$

- Compressor discharge total temperature $\left(T_{3}\right)$

- $\quad$ Turbine exit total pressure $\left(P_{8}\right)$

- $\quad$ Turbine exit total temperature $\left(T_{8}\right)$

- $\quad$ Fuel flow rate $\left(m_{f}\right)$ 
In gas turbine measurement, measured performance parameters include measurement uncertainties, which were well described by Urban and Volponi [1992]. There are two major types of uncertainties: repeatable and non-repeatable uncertainties. Correction techniques for the repeatable uncertainties were described by previous researchers, such as Urban [1972] and Volponi [1982, 2003], and will not be discussed in this paper. Therefore, it is assumed that the operating point used for the engine diagnosis is at its maximum thrust and at standard ambient condition. Measurement noise is inevitable. It is the major non-repeatable uncertainty that cannot be easily corrected and has a negative impact on diagnostic results. To make the analysis more realistic measurement noise is included and simulated.

\begin{tabular}{|l|l|l|}
\hline Measurement & Range & Typical Error \\
\hline Pressure & $3-45$ psia & $\begin{array}{l} \pm 0.5 \% \\
\pm 0.5 \% \text { or } 0.125 \text { psia } \\
\text { whichever is greater }\end{array}$ \\
\hline Temperature & $-65-290 \mathrm{C}$ & $\pm 3.3 \mathrm{C}$ \\
& $290-1000 \mathrm{C}$ & $\pm \sqrt{2.5^{2}+(0.0075 \cdot T)^{2}}$ \\
& $1000-1300 \mathrm{C}$ & $\pm \sqrt{3.5^{2}+(0.0075 \cdot T)^{2}}$ \\
\hline Fuel Flow & Up to $250 \mathrm{~kg} / \mathrm{hr}$ & $41.5 \mathrm{~kg} / \mathrm{hr}$ \\
& Up to $450 \mathrm{~kg} / \mathrm{hr}$ & $34.3 \mathrm{~kg} / \mathrm{hr}$ \\
& Up to $900 \mathrm{~kg} / \mathrm{hr}$ & $29.4 \mathrm{~kg} / \mathrm{hr}$ \\
& Up to $1360 \mathrm{~kg} / \mathrm{hr}$ & $23.7 \mathrm{~kg} / \mathrm{hr}$ \\
& Up to $1815 \mathrm{~kg} / \mathrm{hr}$ & $20.8 \mathrm{~kg} / \mathrm{hr}$ \\
& Up to $2270 \mathrm{~kg} / \mathrm{hr}$ & $23.0 \mathrm{~kg} / \mathrm{hr}$ \\
& Up to $2725 \mathrm{~kg} / \mathrm{hr}$ & $25.9 \mathrm{~kg} / \mathrm{hr}$ \\
& Up to $3630 \mathrm{~kg} / \mathrm{hr}$ & $36.2 \mathrm{~kg} / \mathrm{hr}$ \\
& Up to $5450 \mathrm{~kg} / \mathrm{hr}$ & $63.4 \mathrm{~kg} / \mathrm{hr}$ \\
& Up to $12260 \mathrm{~kg} / \mathrm{hr}$ & $142.7 \mathrm{~kg} / \mathrm{hr}$ \\
\hline
\end{tabular}

Table 1. Measurement noise (Dyson and Doel [1987])

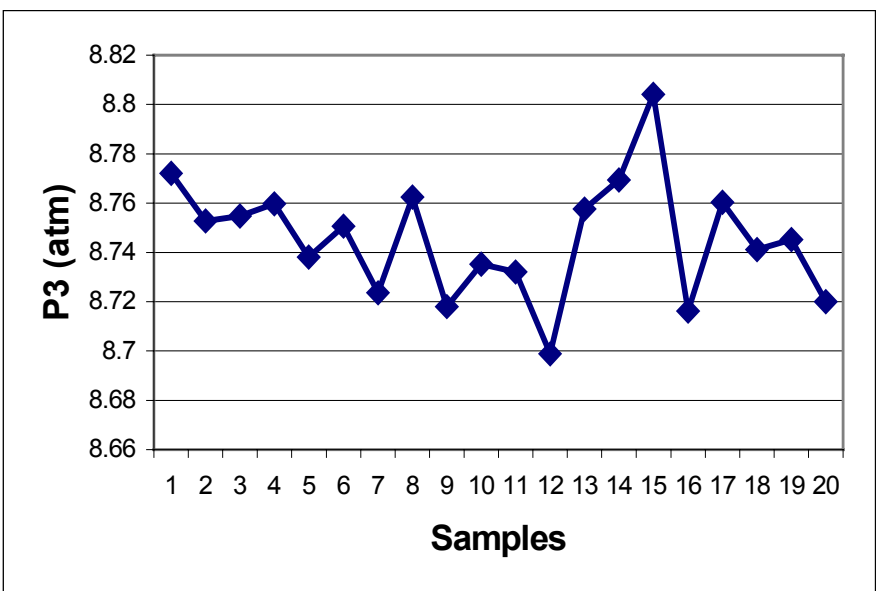

Figure 2. Simulated measurement P3

To simulate the noisy measurements from the model gas turbine engine, the performance of the model engine is first simulated and then the simulated measurable performance parameters are superimposed on by measurement noise. It is assumed that the measurement noise has Gaussian distribution and that the noise levels for the measurable parameters concerned fall within the ranges provided by Dyson and Doel [1984], Table 1. One of the simulated noisy measurements (P3) for the measurable parameters from the model engine is shown in Figure 2.

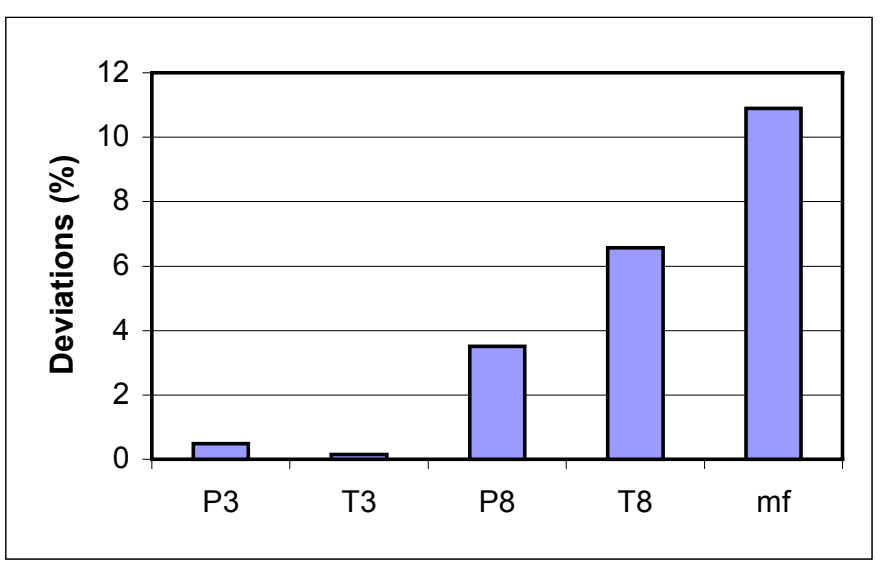

Figure 3. Fault Signature of Turbine Degradation

$$
\left(\Delta \eta_{t}=-1.5 \%, \Delta \Gamma_{t}=-3.5 \%\right)
$$

In order to improve the effectiveness of gas turbine diagnostics, measurement noise reduction techniques must be applied to reduce the impact of measurement noise before GPA is used. Many measurement noise reduction techniques, such as those described by Lu et al. [2000] and Ganguli [2001b], have been developed in the past. A discussion of these techniques is beyond the scope of this paper. Therefore, a simple data averaging method is used in this research to reduce the impact of measurement noise and the mathematical expression for the averaging is shown in Equation (1).

$$
\bar{z}=\frac{1}{M} \sum_{i=1}^{M} z_{i}
$$

where $M$ is the number of measurement samples and in this case $M=20$. The corresponding fault signature calculated with the averaged measurements of the clean and degraded model engine is shown in Figure 3.

\section{GAS PATH ANALYSIS (GPA)}

A linear and non-linear GPA approach developed at Cranfield (Escher [1995]) is an effective gas turbine diagnostic method to assess gas turbine faults. The approach is based on the assumption that a linearized gas turbine performance model, Equation (2), is an accurate description of engine behaviour at certain operating conditions. 


$$
\Delta \vec{z}=H \cdot \Delta \vec{x}
$$

The degradation of components expressed by the deviation of component parameters (flow capacity and efficiency) can be predicted by inverting the influence coefficient matrix (ICM) $H$ to a fault coefficient matrix (FCM) $H^{-1}$ leading to Equation (3).

$$
\Delta \vec{x}=H^{-1} \cdot \Delta \vec{z}
$$

The nonlinearity of the engine behaviour is taken into account by using an iterative process, Escher [1995], where linear GPA is applied iteratively until a converged solution is obtained, Figure 4.

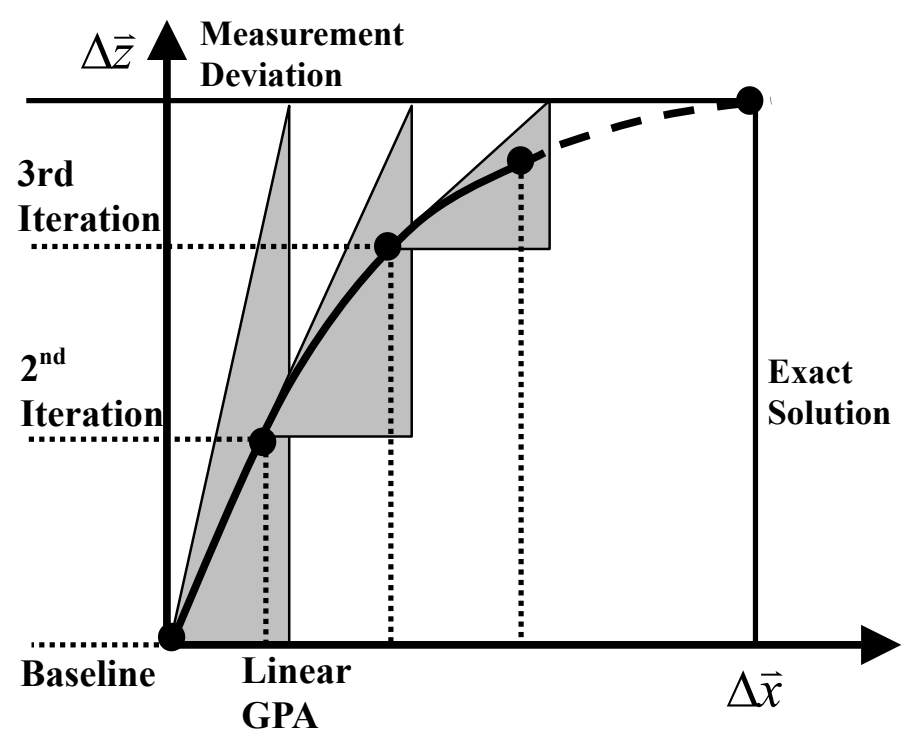

Figure 4. Non-Linear GPA (Escher [1995])

This diagnostic method is simple and fast in prediction although it has certain requirements that are difficult to meet such as:

- determining the influence coefficient matrix (ICM) to accurately describe gas turbine performance

- fault and noise free sensors

- uncorrelated measurements that are sensitive to engine degradation.

Another disadvantage of GPA is the uncertainty of the prediction - conflicting answers may be provided if degraded components are unknown. Therefore, further interpretation of the prediction from GPA may be very important in order to avoid being misled by GPA. This job can only be done by experienced gas turbine diagnostics engineers. To show the severity of the uncertainty, a simulated degradation and diagnostic process with GPA using the model engine is presented as follows.

With TURBOMATCH, the averaged noisy measurements of clean and degraded performance of the engine are obtained and compared with each other. The corresponding fault signature, which is expressed with the deviation of measurable parameters, defined as $\left(\Delta z / z_{n}\right) \times 100 \%$ can be used by GPA to diagnose the fault.

Normally, when gas turbine performance degrades, the degraded components are unknown to the maintenance engineers. Therefore, one of the solutions in diagnostics is to search all the combinations of the potential faulty components, i.e. fault cases, with GPA and interpret the results. For this specific engine, the potential fault cases and the searched results for each of the fault cases with non-linear GPA are shown in Table 2.

It can be seen that conflicting results are shown when different fault cases are searched. For example, the compressor is indicated as degraded in fault cases FC1 and FC4, while the burner is at fault in cases $\mathrm{FC} 2$ and $\mathrm{FC} 4$, and the turbine is at fault in cases FC3, FC5 and FC6. Although it may be more likely that the turbine is degraded according to the preponderance of cases which point to a turbine fault, it is still difficult to rule out the possibility of compressor and burner degradation. It also shows that once the actual degraded component is included in the fault cases (FC3, FC5 and FC6), GPA is able to predict the implanted fault accurately. This is the limitation of GPA. Therefore, a technique to isolate the degraded components will be very useful in improving the

\begin{tabular}{|c|c|c|c|c|c|c|c|}
\hline & $\mathrm{FC1}$ & $\mathrm{FC} 2$ & FC3 & FC4 & FC5 & FC6 \\
\hline \multirow{2}{*}{$\begin{array}{l}\text { Implanted } \\
\text { fault }\end{array}$} & $\eta_{t}$ & & & -1.5 & & & \\
\hline & $\Gamma_{t}$ & & & -3.5 & & & \\
\hline \multirow[t]{2}{*}{ Compressor } & $\eta_{c}$ & -4.74 & & & -4.01 & 0.0 & \\
\hline & $\overline{\Gamma_{c}}$ & -0.70 & & & $\begin{array}{l}-0.60 \\
\end{array}$ & 0.0 & \\
\hline Burner & $\eta_{b}$ & & -5.14 & & -2.62 & & 0.0 \\
\hline \multirow[t]{2}{*}{ Turbine } & $\eta_{t}$ & & & -1.50 & & -1.50 & $\begin{array}{l}-1.50 \\
\end{array}$ \\
\hline & $\Gamma_{t}$ & & & -3.50 & & -3.50 & -3.50 \\
\hline \multicolumn{3}{|c|}{$\begin{array}{l}\text { FC1 - compressor } \\
\text { FC2 }- \text { burner } \\
\text { FC3 }- \text { turbine }\end{array}$} & \multicolumn{5}{|c|}{$\begin{array}{l}\text { FC4 }- \text { compressor }+ \text { burner } \\
\text { FC5 }- \text { compressor }+ \text { turbine } \\
\text { FC6 }- \text { burner }+ \text { turbine }\end{array}$} \\
\hline
\end{tabular}
diagnostic accuracy of GPA and avoiding confusion.

Table 2. Possible faults detected with nonlinear GPA

\section{PATTERN MATCHING METHOD}

Gas turbine component degradation causes deviation to the measurable performance parameters from their baseline values. For a certain chosen instrumentation set, the measurement deviation is used to describe the degradation and normally called a fault signature. Fault signatures are different for different component degradations and therefore this information is used to isolate and distinguish the faults. The 
fault signature corresponding to the implanted turbine fault described in a previous section is shown in Figure 3. In a more general case, a fault signature can be described as a vector $\vec{V}_{0}$, Equation (4), in a multi-dimensional measurement space. A two dimensional vector $\vec{V}_{0}$ is illustrated in Figure 5 .

$$
\vec{V}_{0}=\sum_{j=1}^{N} V_{0 j} \cdot \vec{i}_{j}
$$

The idea of pattern matching for fault isolation is to compare fault signatures corresponding to all possible component degradations with the measured fault signature. The one closest to the actual fault signature indicates the most likely fault.

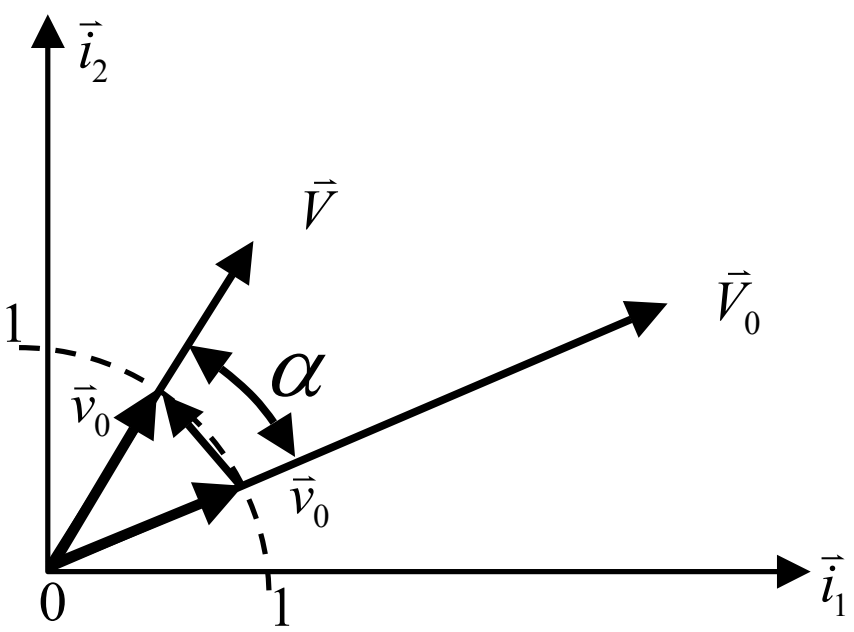

Figure 5. Fault signature vectors

To force the approach to cover all possible component faults, first all major components in the gas turbine must be taken into account. Secondly, all combinations of component faults must be considered in cases where there are multiple component faults. For each fault case, different levels of component degradation must also be taken into account.

To illustrate how the pattern matching method works, the fault signature vector $\vec{V}$, Equation (5), corresponding to one of the fault cases is compared with the actual fault signature $\vec{V}_{0}$ (Figure 3).

$$
\vec{V}=\sum_{j=1}^{N} V_{j} \cdot \vec{i}_{j}
$$

Taking into account that faults of the same type, but with different levels of component degradation, may have correlated fault signature vectors, the fault signature vectors $\vec{V}$ and $\vec{V}_{0}$ are scaled to unity vectors $\vec{v}$ and $\vec{v}_{0}$ respectively, as shown in Equations (6) and (7).

$$
\begin{aligned}
& \vec{v}=\frac{\vec{V}}{|\vec{V}|}=\sum_{j=1}^{N} v_{j} \cdot \vec{i}_{j}=\sum\left(\frac{V_{j}}{|\vec{V}|}\right) \cdot \vec{i}_{j} \\
& \vec{v}_{0}=\frac{\vec{V}_{0}}{\left|\vec{V}_{0}\right|}=\sum_{j=1}^{N} v_{0 j} \cdot \vec{i}_{j}=\sum\left(\frac{V_{0 j}}{\left|\vec{V}_{0}\right|}\right) \cdot \vec{i}_{j}
\end{aligned}
$$

In order to make sure that vectors $\vec{V}$ and $\vec{V}_{0}$ represent similar gas turbine component faults, the following criteria are established:

Criterion 1: Matching Displacement Factor $(M D F)$ must be small enough. Matching Displacement Factor was used by Lee and Singh [1996] and is defined as the norm of the vector $\left(\vec{v}-\vec{v}_{0}\right)$ :

$$
M D F=\left|\vec{v}-\vec{v}_{0}\right|=\sqrt{\sum_{j=1}^{N}\left(v_{j}-v_{0 j}\right)^{2}}<\sigma_{1}
$$

Criterion 2: Similarity Factor $(S F)$ must be close to unity. Similarity Factor was used by Provost and Singh [1995] and Lee and Singh [1996] and is defined as the dot product of the vectors $\vec{v}$ and $\vec{v}_{0}$ :

$$
S F=\vec{v} \bullet \vec{v}_{0}=\sum_{j=1}^{N} v_{j} \cdot v_{0 j}
$$

and

$$
1 \geq S F>\sigma_{2}
$$

Physically the Similarity Factor $S F$ is the cosine of the angle $\alpha$ between the two vectors $\vec{V}$ and $\vec{V}_{0}$. When $S F$ is close to unity, the two vectors are pointing in almost the same direction, which means that they represent the same type of gas turbine fault.

Lee and Singh [1996] used the above two criteria and successfully isolated and quantified certain fault cases for a turbofan engine. Unfortunately, it is found that in some cases when some elements of similar fault signatures produced by different component faults are close to zero, the above two criteria cannot distinguish them. Therefore, two more criteria are introduced and they are described as follows:

Criterion 3: The Maximum Ratio of Fault Signature Elements (MRFSE) must not exceed a certain level. This criterion can be expressed as:

$$
\max \left\{\left(v_{j} / v_{0 j}\right),\left(v_{0 j} / v_{j}\right)\right\}<\sigma_{3}
$$

where $\mathrm{j}=1$ to $\mathrm{N}$.

Criterion 4: All the corresponding Fault Signature Elements (SFSE) must have the same sign, either positive or negative. This criterion can be expressed as 


$$
\begin{gathered}
v_{j} \cdot v_{0 j}>0 \\
\text { if } \quad \min \left\{\left|v_{j}\right|,\left|v_{0 j}\right|\right\}>\sigma_{4}
\end{gathered}
$$

where $j=1$ to $N$.

In the criteria, the selection of the values of the thresholds $\sigma_{1}, \sigma_{2}, \sigma_{3}$ and $\sigma_{4}$ is crucial to the success of the approach. The magnitude of the threshold values should be selected by taking into account

- the sensitivity of the instruments to engine degradation and

- the level of scattering of discrete potential faults.

In general, selected measurements should be sensitive to engine degradation and the level of scattering of the potential faults should be compromised between fault isolation accuracy and computing time. Use of a large number of discrete potential faults will improve the accuracy of fault isolation but increase computing time, and vice versa. Suggested ranges of the threshold values are listed in Table 3.

\begin{tabular}{|c|c|c|c|}
\hline$\sigma_{1}$ & $\sigma_{2}$ & $\sigma_{3}$ & $\sigma_{4}$ \\
\hline $0.02-0.10$ & $0.90-0.99$ & $2.0-5.0$ & $0.1-0.4$ \\
\hline
\end{tabular}

Table 3. Suggested values of thresholds

\begin{tabular}{|l|c|c|c|c|}
\hline & SF & MDF & MRFSE & SFSE \\
\hline Criteria & $>0.95$ & $<0.05$ & $<2.0$ & $\begin{array}{c}>0.0 \\
\sigma_{4}=0.2\end{array}$ \\
\hline $\begin{array}{l}\text { Fault Case 1: } \\
\text { Turbine } \\
\Delta \eta_{t}=-2 \% \\
\Delta \Gamma_{t}=-4 \%\end{array}$ & 0.9999 & 0.0156 & 1.2629 & $>0.0$ \\
\hline $\begin{array}{l}\text { Fault Case 2: } \\
\text { Turbine \& } \\
\text { Burner } \\
\Delta \eta_{t}=-2 \% \\
\Delta \Gamma_{t}=-4 \%\end{array}$ & 0.9989 & 0.0469 & 1.2051 & $>0.0$ \\
$\Delta \eta_{b}=-1 \%$ & & & & \\
\hline
\end{tabular}

Table 4. Two similar fault cases

In order to use the above approach effectively, compromises have to be made between the accuracy of the fault isolation and computing time. In the case where a diagnostic problem becomes increasingly complicated as multiple component faults are taken into account, larger numbers of potential faults for a certain fault case in the pre- defined degradation range will improve the prediction accuracy. However, this will take a longer computing time.

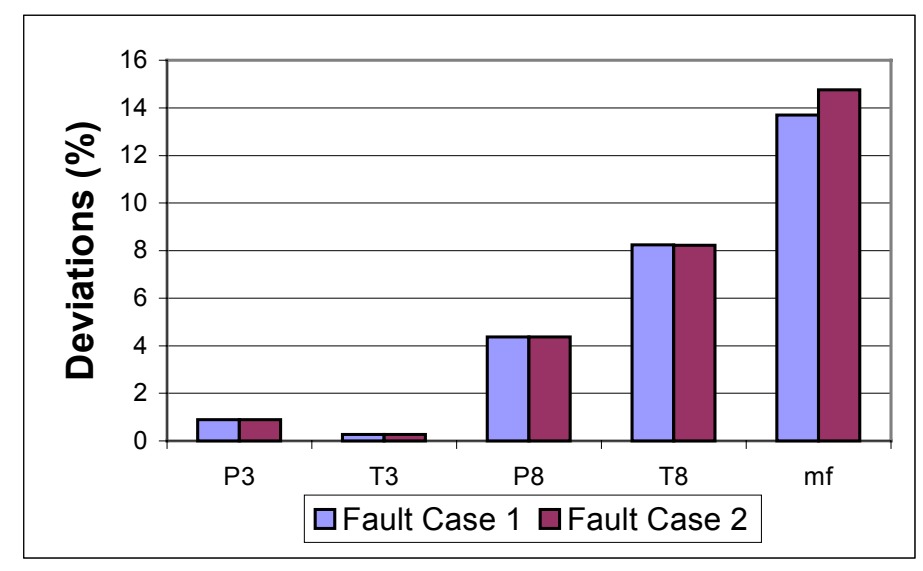

Figure 6. Fault signatures of Fault Cases $1 \& 2$

Due to the fact that the approach only compares the actual fault signature with the fault signatures of a limited number of discrete potential faults, based on pre-defined thresholds of isolation criteria, it is likely that more than one fault cases are predicted as the possible fault. This can be seen in Table 4 where, for the fault implanted in the model engine, a single component fault case and a dual component fault case both satisfy the thresholds of the isolation criteria defined in Table 4 . Likewise, the fault signatures of the two fault cases are very similar, Figure 6. The reason for such a similarity is that the turbine fault contributes dominantly to the major part of the fault signature while the burner fault only contributes very little. With the criteria used in this study, it is very difficult to distinguish these two fault cases. Therefore, it would be better to use pattern matching as an initial filter in the diagnostic process to locate the most likely degraded components and then use another diagnostic technique such as GPA for further fault assessment. In the following section, such an approach is proposed.

\section{ENHANCED GPA APPROACH}

The basic theory, the advantages and the disadvantages of GPA, and the pattern matching method have been described in previous sections. In this section, a fault isolation enhanced GPA approach is suggested and the idea of the approach is illustrated in Figure 7.

In this approach, once the fault signature calculated with averaged noisy measurements is available, the diagnostic process is carried out in two steps. The first step is to isolate degraded components or filter the least likely component faults by using the pattern matching method. The second step is to apply nonlinear Gas Path Analysis to refine and quantify the component fault. Due to the fact that the pattern matching 
method already points out the most likely degraded components, the application of GPA to quantify the fault becomes much easier and the confusing situation shown in Table 2 can be avoided. A case study using the enhanced GPA diagnostic approach to the diagnostic process for the model gas turbine engine is shown in the next section.

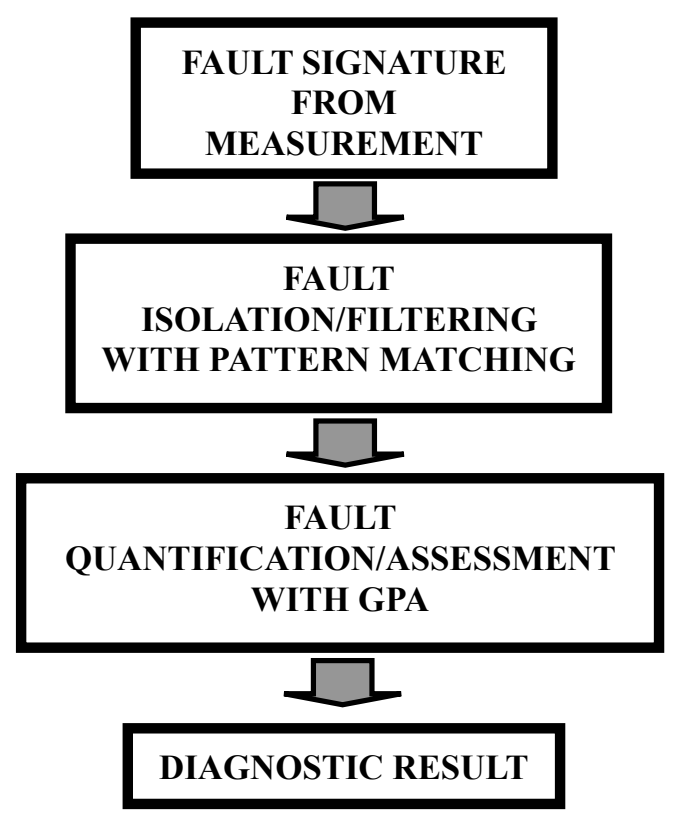

Figure 7. Enhanced GPA procedure

\section{APPLICATION AND ANALYSIS}

A model aero gas turbine engine similar to Rolls Royce aero AVON described in a previous section is used to test the effectiveness of the fault isolation enhanced GPA approach. In the diagnostic analysis, the potential degraded components are the compressor, the burner and the turbine. It is assumed that only single and dual component faults are likely and therefore six fault cases in total are considered to cover all the possible faults, Table 5 .

With Cranfield TURBOMATCH performance simulation code the clean and degraded engine performance can be simulated and the possible range of the degradation for each of the degraded component parameters is described in Table 5. A turbine degradation is assumed and the turbine degradation with $1.5 \%$ drop in isentropic efficiency and 3.5\% drop in flow capacity is implanted into the model engine. Noisy measurements are then simulated (Figure 2) and the fault signature calculated with the averaged noisy measurements (Figure 3) can be obtained.

\begin{tabular}{|c|c|c|c|c|}
\hline & & $\begin{array}{l}\text { Degraded } \\
\text { Parameters }\end{array}$ & $\begin{array}{l}\text { Searching } \\
\text { range (\%) }\end{array}$ & $\begin{array}{l}\text { Step } \\
(\%)\end{array}$ \\
\hline \multirow[t]{2}{*}{$\mathrm{FC} 1$} & \multirow[t]{2}{*}{ Compressor } & $\Delta \eta_{c}$ & $-5.0-0.0$ & \multirow{15}{*}{1.0} \\
\hline & & $\Delta \Gamma_{c}$ & $-5.0-0.0$ & \\
\hline $\mathrm{FC} 2$ & Burner & $\Delta \eta_{b}$ & $-5.0-0.0$ & \\
\hline \multirow[t]{2}{*}{ FC3 } & \multirow[t]{2}{*}{ Turbine } & $\Delta \eta_{t}$ & $-5.0-0.0$ & \\
\hline & & $\Delta \Gamma_{t}$ & $-5.0-5.0$ & \\
\hline \multirow[t]{3}{*}{$\mathrm{FC4}$} & \multirow[t]{2}{*}{ Compressor } & $\Delta \eta_{c}$ & $-5.0-0.0$ & \\
\hline & & $\Delta \Gamma_{c}$ & $-5.0-0.0$ & \\
\hline & Burner & $\Delta \eta_{b}$ & $-5.0-0.0$ & \\
\hline \multirow[t]{4}{*}{ FC5 } & \multirow[t]{2}{*}{ Compressor } & $\Delta \eta_{c}$ & $-5.0-0.0$ & \\
\hline & & $\Delta \Gamma_{c}$ & $-5.0-0.0$ & \\
\hline & \multirow[t]{2}{*}{ Turbine } & $\Delta \eta_{t}$ & $-5.0-0.0$ & \\
\hline & & $\Delta \Gamma_{t}$ & $-5.0-5.0$ & \\
\hline \multirow[t]{3}{*}{ FC6 } & Burner & $\Delta \eta_{b}$ & $-5.0-0.0$ & \\
\hline & \multirow[t]{2}{*}{ Turbine } & $\Delta \eta_{t}$ & $-5.0-0.0$ & \\
\hline & & $\Delta \Gamma_{t}$ & $-5.0-5.0$ & \\
\hline
\end{tabular}

Table 5. Fault cases in concern

In the first step of the diagnostic approach shown in Figure 7 using the pattern matching method, the fault signature is compared with all the discrete potential fault cases within the ranges defined in Table 5. A discrete step in Table 5 is used to define the scattering of the discrete points within the degradation range. With certain thresholds for the isolation criteria defined in Table 4, two most likely fault cases are predicted by the pattern matching method, one is a single turbine fault and the other is a combined burner and turbine fault shown in Tables 4 and 6 . Therefore, the fault diagnostic analysis now can be focused on possible turbine degradation with slight burner degradation.

In the second step of the diagnostic procedure, two diagnostic calculations are carried out with the non-linear GPA to assess the quantity of the fault, one focusing on the turbine only and the other focusing on the burner and the turbine. The diagnostic results of these two predictions are shown in Table 6 and also compared with the predictions from the pattern matching method and the implanted fault. It is obvious that the two predictions with the non-linear GPA provide the same diagnostic result, showing that the degraded component is the turbine. 


\begin{tabular}{|c|c|c|c|c|}
\hline & \multicolumn{2}{|c|}{ Fault Cases } & Degraded & Degradation \\
\hline \multirow{2}{*}{$\begin{array}{l}\text { Implanted } \\
\text { fault }\end{array}$} & & \multirow[t]{2}{*}{ Turbine } & $\Delta \eta_{t}$ & -1.5 \\
\hline & & & $\Delta \Gamma_{t}$ & -3.5 \\
\hline \multirow{5}{*}{$\begin{array}{l}\text { Pattern } \\
\text { Matching } \\
\text { Prediction }\end{array}$} & \multirow[t]{2}{*}{1} & \multirow[t]{2}{*}{ Turbine } & $\Delta \eta_{t}$ & -2.0 \\
\hline & & & $\Delta \Gamma_{t}$ & -4.0 \\
\hline & \multirow[t]{3}{*}{2} & Burner & $\Delta \eta_{b}$ & -1.0 \\
\hline & & \multirow[t]{2}{*}{ Turbine } & $\Delta \eta_{t}$ & -2.0 \\
\hline & & & $\Delta \Gamma_{t}$ & -4.0 \\
\hline \multirow{5}{*}{$\begin{array}{l}\text { Non-Linear } \\
\text { GPA } \\
\text { Prediction }\end{array}$} & \multirow[t]{2}{*}{1} & \multirow[t]{2}{*}{ Turbine } & $\Delta \eta_{t}$ & -1.5015 \\
\hline & & & $\overline{\Delta \Gamma_{t}}$ & -3.5013 \\
\hline & \multirow[t]{3}{*}{2} & Burner & $\Delta \eta_{b}$ & -0.0 \\
\hline & & \multirow[t]{2}{*}{ Turbine } & $\Delta \eta_{t}$ & -1.4993 \\
\hline & & & $\Delta \Gamma_{t}$ & -3.5005 \\
\hline
\end{tabular}

\section{Table 6. Comparison between implanted and} predicted fault

It can be seen that the pattern matching method can isolate the degraded components effectively but can only provide an approximate estimation of the degradation. On the other hand, it is difficult for GPA to locate the degraded components. However once the degraded components are located, non-linear GPA is able to provide a very good quantitative assessment of the degradation. Therefore, the combination of the pattern matching method and the non-linear GPA offers a much more effective way of gas turbine fault diagnosis.

The proposed diagnostic approach has only been applied to a model aero gas turbine with a simple configuration, and has shown a promising result. It is the intention of the author to extend the application of the approach to different gas turbine engines with different fault cases.

The computation time for fault isolation using the pattern matching method is about 6 seconds on a DAN personal computer (Pentium III) for single component faults and 100 seconds for single and dual component faults. The computation time used by non-linear GPA is only a few seconds.

\section{CONCLUSIONS}

In this study, an enhanced Gas Path Analysis approach for gas turbine diagnostics has been developed. It includes two steps in the diagnostic process; the first step is the component fault isolation, where a pattern matching method is used. The second step is the quantification of the degradation of the isolated faulty components, where a non-linear GPA is applied. The developed pattern matching method includes four isolation criteria and the corresponding thresholds for effective fault isolation have been suggested. The proposed diagnostic approach has been applied to the diagnostic process of a model aero gas turbine engine implanted with a typical turbine fault and shown a promising result. More applications of the proposed diagnostic approach to different gas turbines with different faults are necessary.

\section{AKNOWLEDGEMENTS}

The present research is supported by a Platform Grant of the Engineering and Physical Sciences Research Council (EPSRC), United Kingdom.

\section{REFERENCES}

[1] Dyson R.J.E. and Doel D. L., "CF-80 Condition Monitoring - The Engine Manufacturing's Involvement in Data Acquisition and Analysis", AIAA-84-1412, 1987.

[2] Denny G., "F16 Jet Engine Trending and Diagnostics with Neural Networks", Proceedings of SPIE - The International Society for Optical Engineering, Vol. 1965, pp. 419-422, 1993.

[3] Doel D.L., "Gas Path Analysis - Problems and Solutions", Symposium of Aircraft Integrated Monitoring Systems, Bonn, Germany, 21-23 September 1993.

[4] Escher P.C., "Pythia: An Object-Oriented Gas Path Analysis Computer Program for General Applications", Ph.D. Thesis, Cranfield University, October 1995.

[5] Ganguli R., "Application of Fuzzy Logic for Fault Isolation of Jet Engines", ASME Paper 2001-GT-0013, 2001a.

[6] Ganguli R., "Data Rectification and Detection of Trend Shifts in Jet Engine Gas Path Measurements Using Median Filters and Fuzzy Logic", ASME 2001-GT-0014, 2001b.

[7] Gulati A., Taylor D. and Singh R., "Multiple Operating Point Analysis Using Genetic Algorithm Optimisation for Gas Turbine Diagnostics", ISABE-2001-1139, $14^{\text {th }}$ ISABE, 2001.

[8] Lee Y.H. and Singh R., "Health Monitoring of Turbine Engine Gas Path Component and Measurement Instrumentation", ASME Paper 96-GT-242, 1996.

[9] Li Y. G., 2002, "Performance-Analysis-Based Gas Turbine Diagnostics: a Review", Proceedings of the IMechE: Journal of Power and Energy, Vol. 216, No. A5.

[10] Li Y. G., "A Gas Turbine Diagnostic Approach with Transient Measurements", Proceedings of IMechE: Journal of Power and Energy, Vol. 217, No. A1, pp. 169177, 2003. 
[11] Lu P.-J., Zhang M.-C., Hsu T.-C. and Zhang J., "An Evaluation of Engine Faults Diagnostics Using Artificial Neural Networks", ASME 00-GT-029, 2000.

[12] Macmillan W. L., "Development of a Modular Type Computer Program for the Calculation of Gas Turbine Off Design Performance", Ph.D. Thesis, Cranfield University, September 1974.

[13] Marinai L., Singh R. and Curnock B., "Fuzzy-LogicBased Diagnostic Process for Turbofan Engines", ISABE2003-1149, 15 ${ }^{\text {th }}$ ISABE, 2003.

[14] Mathioudakis K., "Non Linear Methods for Gas Turbine Fault Diagnostics", Von Karman Institute Lecture Series "Gas Turbine Condition Monitoring and Fault Diagnosis", VKI LS 2003-01, Jan 13-17, 2003.

[15] Ogaji S.O.T. and Singh R., "Gas Path Fault Diagnosis Framework for a Three-Shaft Gas Turbine", Proceedings of IMechE: Journal of Power and Energy, Vol. 217, No. A1, pp. 149-157, 2003.

[16] Provost M. J. and Singh R., "Gas-Path Analysis: Preparing for Success", AIDAA/AAAF/DGLR/RAeS $5^{\text {th }}$ European Propulsion Forum, Pisa, Italy, April 1995.

[17] Sampath S., Gulati A. and Singh R., "Fault Diagnostics Using Genetic Algorithm for Advanced Cycle Gas Turbine", ASME Paper GT-2002-30021, 2002.

[18] Singh R., "Advances and Opportunities in Gas Path Diagnostics", ISABE-2003-1008, 15 ${ }^{\text {th }}$ ISABE, 2003.

[19] Stamatis A., Mathioudakis K. and Papailiou K.D., "Adaptive Simulation of Gas Turbines Performance", ASME Paper 90-GT-205, 1990.

[20] Urban L. A., "Parameter Selection for Multiple Fault Diagnostics of Gas Turbine Engines", J. Eng. Power, pp. 225-230, April 1975.

[21] Urban L. A. and Volponi A. J., "Mathematical Methods of Relative Engine Performance Diagnostics", SAE 1992 Transactions Journal of Aerospace, Section 1, Vol. 101, SAE Technical Paper No. 922048, 1992.

[22] Urban L. A., "Gas Path Analysis Applied to Turbine Engine Condition Monitoring”, AIAA Paper 72-1082, 1972.

[23] Volponi A.J., "Gas Path Analysis: An Approach to Engine Diagnostics", $35^{\text {th }}$ Symposium Mechanical Failure Prevention Group, Gaithersbury, MD, April 1982.

[24] Volponi A. J., "Gas Turbine Condition Monitoring \& Fault Diagnosis", Von Karman Institute Lecture Series "Gas Turbine Condition Monitoring and Fault Diagnosis", VKI LS 2003-01, Jan 13-17, 2003.

[25] Wilkenson P. H., "Aircraft Engines of the World 196061”, pp.135, 1960.

[26] Zedda M. and Singh R., "Gas Turbine Engine and Sensor Diagnostics", ISABE 99-7238, $13^{\text {th }}$ ISABE, 1999a.

[27] Zedda M. and Singh R., "Gas Turbine Engine and Sensor Fault Diagnosis Using Optimisation Techniques", AIAA99-2530, 1999b. 
2004-07

\title{
Gas turbine diagnosis using a fault isolation enhanced GPA
}

\author{
Li, Yiguang
}

ASME

Li YG, Gas turbine diagnosis using a fault isolation enhanced GPA, Proceedings of ASME Turbo Expo 2004: Power for Land, Sea, and Air (GT2004), 14-17 July 2004, Vienna, Austria, Volume 7, pp. 361-369, Paper number GT2004-53571

http://dx.doi.org/10.1115/GT2004-53571

Downloaded from Cranfield Library Services E-Repository 